\title{
Examining the Ethical Environment in Higher Education
}

\begin{abstract}
Higher Education Institutions across the world have found themselves faced by new challenges on issues of ethics. Much of this has been centred on issues of assessment: plagiarism, buying essays, sharing/lending of previously passed work and, the stealing of marked/returned work of others. Institutions still treat academic misconduct as a largely behavioural difficulty rather than an issue of ethics (or education) suggesting that academia places a far greater emphasis on combating new forms of dishonesty than it does on encouraging ethical habits and a healthy ethical environment.
\end{abstract}

To date, the majority of research in this area has examined these forms of academic misconduct from the point of view of the student and/or the university with the perspective of academics receiving very limited attention. Our hypothesis is that academics are perhaps best placed to provide the education needed to create and sustain an ethical environment and we argue that being 'ethically aware' is a critical factor in the development of academic competence for all parties.

This study adds to existing research in three ways: firstly, by highlighting the importance of an overall framework for an ethical environment within HEls; secondly, by suggesting an ecological model of key parties (the university, students and academics) with responsibility for this environment in assessment; thirdly, by including new evidence (generated by a survey of academics) to extend our understanding of their views on these issues.

\section{Introduction}

In March 2017, 270 final year medical students at the University of Glasgow were told that they would have to retake their end-of-course practical assessment after purported online collusion. Students who had taken the tests early reportedly used social media to discuss the scenarios faced for the benefit of those who had yet to take the assessment. (Bodkin, 2017)1

A veritable tsunami of issues have come together in recent years to challenge previously held principles on systemic integrity in HEls across much of the western world. This is exemplified by shrinking employment possibilities for those without a university degree; the 'high-stakes testing' of secondary education feeding in to the commodification of higher degrees; the enormous financial burden students face for studying; and the positioning of students as customers or consumers whose interactions are governed by contracts. Universities have always faced some ethical challenges such as academics falsifying research data or students stealing exam papers in advance of a test, but concerns about these practices have been heightened by the high-stakes nature of a university education such as: sharing of confidential assessment data in online environments (see Bodkin, 2017 above), plagiarism, buying essays, covert sharing/lending of work and the stealing of marked/returned work.

The paucity of an overall account within which these issues can be framed often leaves researchers unable to connect with the ethical values that underpin what is claimed to be "the war against academic dishonesty" (Zwagerman 2008:

\footnotetext{
${ }^{1}$ http://www.telegraph.co.uk/news/2017/03/27/medical-students-atuniversity-glasgow-told-resit-exam-collusion/
} 
676). Institutions still treat academic misconduct as a largely behavioural difficulty rather than an issue of ethics (or education) (Allen, Fuller et al. 1998) suggesting that academia places a far greater emphasis on combating new forms of dishonesty than it does on encouraging ethical habits and a healthy ethical environment. This could give the impression that universities are simply fire fighting outbreaks of academic dishonesty as the sole means of sustaining the ethical environment of assessment. In reality they are attempting to do so much more.

We propose that a healthy ethical environment is needed for academia to function and to maintain its values and it is often the voices of academics that can play a crucial part in this ethical milieu. We believe that acting ethically goes beyond avoiding plagiarism, correct referencing and stylistic approaches to academic writing. It can raise uncomfortable questions as to just how students might be encouraged to develop the values underpinning academic integrity and consequently, how academics ensure that they abide by this without creating a punitive atmosphere.

This paper explores the ethical environment of the university drawing links to the existing literature to support a triadic model of the ecology. This study makes an important contribution to existing research in three ways: firstly, by providing an overall framework in which to position the existing research - the ethical environment; secondly, by suggesting a triadic ecological model of the major parties with responsibility for this environment in assessment - the university, the students and the academics; thirdly, by incorporating data from research with academics in the UK context. ${ }^{2}$

\section{Understanding the ethical environment}

To date, there has been scant philosophical attention paid to the use of ecological models as a way of understanding ethical issues, despite their wide usage in medicine, psychology, and the humanities (Hogue 1984; Visser 2007; Warren and Cheney 1991). Yet these models are often distinguished by the ways in which they bring together both policy and practice: for example, codes, regulations, rules, the physical environment, intrapersonal issues (Sallis and Sallis 1988). Because of this, we adopted the metaphor of an ecology in order to explore the intrapersonal relationships that provide the protection of the overall environment. Many of these form frameworks for studying particular issues/problems in a multidimensional way in which attention is focussed on a wide variety of explanations. This metaphor may prove a suitable lens through which to examine assessment in the overall ethical environment of the university.

Ecological models have proved to be helpful for examining issues that might have previously been perceived as separate parts of an ethical landscape (McCarthy 2012). Previous research in this area claims that such approaches provide a more holistic view of the issues and extend the analysis to consider the consequences (Raisner 1997, Meyers 2004). Indeed, Raisner (1997) argues that such approaches

\footnotetext{
${ }^{2}$ Of the empirical research cited in this article, 18 studied students and their attitudes/behaviours; six looked at the attitudes/responses of academics and/or dilemmas faced by faculty. All but five (which were from Europe and New Zealand, and all were with students) were undertaken in the USA/Canada. None of the studies reported on here were based in the UK where there is at present a paucity of research, particularly research exploring the attitudes of academics in the UK.
} 
allow us to go beyond systems of ethics and good/bad behaviour to focus on dealing with the practical problems invoked in such debates.

Most discussions of the 'environment' tend to emphasise a physical environment; other common uses highlight social interactions through studying the social environment. So, what exactly do we mean by an ethical environment? First, we are not using the term 'ethical' environment as a way of distinguishing it from an unethical environment but as a way to establish characteristics that define its reach. Secondly, we wish to distinguish this from other similar concepts such as ethos, atmosphere, ${ }^{3}$ ethical climate or even beliefs and ideas about social relationships and interactions. Thirdly, values are embedded in both the practices and institutions that adopt them and are essential for their proper functioning. But these need not always be the same values as held by those who work there. By studying the overall landscape, considering how universities, student and their staff conceptualise their values and attitudes, we intend to reveal a discrete ethical ecology working in this area.

We all exist in an ethical environment framed by the ideas on how we should live; ideas about this may not be fully articulated by individuals, but they set the context for how we think and act. As Haydon (2004:118) explains

...the ethical environment is always there; we cannot live outside of it. Particular individuals may ignore particular aspects of it-someone might for instance be indifferent to moral notions in the narrow sense... but the same person will still live in an environment of ideas about how to live, what is important and so on.

Haydon (2004) suggests that there could be a multiplicity of ethical environments that interact with one another, and this opens up the possibility of the university as having a particular ethical environment that is unique to its situation, but still forms part of a larger overall ethical environment.

Providing a strong ethical environment that promotes ethical decision-making often comprises a plethora of beliefs and expectations, of ideologies and values, attitudes and norms (Arnold, Lampe et al. 2000, Dalton and Radtke 2013). Evaluating the health of this environment involves considering the issues from the stance of all participants in the ecology: in this case, the institution, the students and the academics. Failure to accommodate any one group could potentially create a weakness, not only within the ecology, but across the whole ethical environment. As Haydon (2006) cautions, it is often a lack of clarity around our understanding of rules and responsibilities that can lead to an erosion of the ethical environment. A key factor in this is what institutions and academic staff say they value and what they actually enact in terms of assessment: policies can only have effective value when they match the actions of those using them. This means that in order to study the ethical environment; one would need to look at the overall organisational culture and the behaviour of those who work there (Arnold, Lampe et al. 2000, Meyers 2004).

Responsibility for upholding the wider ethical environment of HEls is often devolved to the academic staff and the students. Other actors, for example administrators or librarians, within HEls may have an impact on the ethical

\footnotetext{
${ }^{3}$ This is particularly the case in education wherein the 'ethos' of a school plays a major role in transmitting values.
} 
environment too. Similarly, it is important to note that unethical behaviour is not solely the domain of students; the university and academic staff may also act unethically on occasions, yet it is student misdemeanours that still merit widespread attention in both research and policy.

\section{The university}

Universities across the world no longer function simply as repositories of knowledge, nor as communities of scholars. The swift transition from elite to mass education and the increased marketisation of $\mathrm{HE}$ in recent decades has diluted Newman's classic account of the university (Newman, Turner et al. 1996). This transition reframes what historically, have been accepted by communities of scholars, as a distinct set of values existing within universities; a realignment has taken place seeking to bring it more inline with dominant values across broader society. Whilst the particular values of the university originally evolved from a distinct sense of purpose of what a university was, as Collini (2012) notes, this purpose is now challenged and lacks clarity. Similarly, Oakeshott's conceptualisation of the university as an 'interval' in life (for the undergraduate) in which to learn to live a more 'significant' life also depicts a world that seems to be receding (Oakeshott 2004). The emphasis upon graduate employability and the marketisation of higher education reframes this ideal into highly utilitarian functions, whereby the 'good life' for students is now characterised by access to desired and desirable professions and jobs (Dore 1979, Love 2008, Tomlinson, 2010).

Much of the current literature focused on ethical behaviour in universities still identifies what we term the 'big three' as being of significant concern: plagiarism, cheating and fraud (Dowling 2003, Brown and Mclnerney 2008, Coren 2012). Research by Nijhof et al (2012) suggests two ways in which HEls generally address these problems. First, by having formal ethical policies and employing personnel charged with upholding institutional ethics in daily decision and policy-making practices. Secondly, the willingness of institutions' management to uphold such an ethos and culture. These two approaches are sometimes described as preventing unethical behaviour (compliance) and promoting ethical behaviour (education).

\section{Compliance}

Compliance based approaches emphasise programmes designed to "prevent, detect and punish violations of pre-set standards of behaviour, especially in the area of law and organisational norms" (Nijhof et al. 2012, 98). Theorists such as Howard (2004) critique this approach as being somewhat reductive in that we risk seeing all students as 'would-be criminals' and our role as academics as 'policing' them. Perhaps more importantly, it may give the simplistic impression that by avoiding particular identified activities, a healthier ethical environment is automatically sustained.

Globally, HEls achieve compliance by reference to general codes of conduct, disciplinary systems or codes of ethics that can be applied to both students and/or employees. Such regulations are often given a privileged status by institutionalising a conception of acceptable behaviour, outlining what is not acceptable, and listing the subsequent penalties. Whilst codes and policies tend to be freely available to students, they are often written in highly legalistic language so it is perhaps unsurprising that students often struggle to understand them. Whilst research 
suggests that a lack of understanding may be associated with high levels of dishonesty (McCabe and Trevino 1993), classifying such behaviour as 'dishonest' can be problematic; ignorance of policies and regulations does not necessarily lead to acting with the intent to deceive.

Codes can undoubtedly help clarify ethical thinking for some, and serve to educate a targeted population in desired standards of behaviour. There are merits to such systems: for example, having a code can have a positive impact on perceptions of ethical behaviour, even when users might not recall specific aspects of it (McCabe and Trevino 1996, Adams et al. 2001, McCabe et al. 2002). Similarly, having a code can be useful for having something to refer students to when troublesome issues arise (Auger 2013), but codes are not always the best way to address ethical issues. Formal codes cannot cover all situations that might arise and this can leave universities trying to address new types of misconduct, particularly those using new technologies, without adequate policies. Codes can also institutionalise an approach to ethics (Small 2001) and in a university context, this risks staff and students becoming less able to think and act independently in new situations or where it is unclear how the rules might apply.

\section{Education}

Whilst the prevalence and scope of academic unethical behaviour amongst students has long been studied and reported on (McCabe, 2001; Malgwi and Rakovski 2009), the same attention has not always been given to educating for or inculcating a sense of ethical integrity in students. Some disciplines, e.g., business, law, medicine, journalism, include ethics within their curriculums because it is felt to be important that their students need to be taught how to think ethically in order to influence ethical actions (Spain and Robles 2011, Lavine and Roussin 2012, Trautner and Borland 2013). A common principle of such programmes is that ethics and personal integrity are at the heart of the normative description of ourselves as moral actors: that there are moral and ethical dimensions fundamental to social responsibility and to the professional identity of people in these professions.

\section{The ethical environment: students}

Over a decade ago, Westacott (2008) suggested that the growth of academic dishonesty in assessment processes was symptomatic of the approach students were encouraged to take to cope with a strictly instrumental view of education. This chimes with the UK experience in which concerns are often voiced in terms that "students seek to secure a degree, rather than experience an education, with their goals limited to the acquisition of skills needed for employment and maximizing income" (Natale and Doran 2012, 188). In recent years, universities have emphasised post-graduation employability and skills with the expectation that these will be embedded into taught modules. However, such an approach can encourage students to see $\mathrm{HE}$ as strictly a financial investment with expectations of a guaranteed return. Yet such instrumentality can be an unwitting failure on the part of universities to adequately induct students into the relevant part of the ethical environment and it requires serious consideration.

To date, a tranche of research has examined academic misconduct from the point of view of the student (Malgwi and Rakovski 2009, Smyth, Davis et al. 2009, 
Comas-Forgas and Sureda-Negre 2010). We have evidence for why students cheat (Malgwi and Rakovski 2009), how they cheat (Comas-Forgas and Sureda-Negre 2010), when they cheat (McCabe and Trevino 1996, Walker 2010), where they do it (McLafferty and Foust 2004) and how they justify it (Molnar and Kletke 2012). As the use of plagiarism detection software (such as Turnitin) has become more widely used in HEls, students know that they can no longer simply cut and paste information from the Internet. However, Walker (2010) suggests an alternative interpretation of such events: that the use of such software may just have encouraged students to become better at cheating. Counter intuitively, he found that novice students plagiarised less than those in their final year, suggesting that some students actually refined their methods of cheating as they progressed. Similarly, research by Molnar and Kletke (2012: 211) found that over time "...students are more willing to cheat and increasingly less concerned about doing so". However, they suggested that students perceived plagiarism in a different way to other types of cheating: that stealing a handbag was unacceptable, but stealing words was not viewed in the same way.

This tension between the compliance and education with institutional demands seems to have no obvious answer. Löfström makes the point that because universities frequently overemphasise the avoidance of plagiarism, students fail to grasp the reasoning behind key academic writing "... and consequently do not comprehend the underlying functions of proper citation and referencing as they pertain to advancing knowledge in the field" (Löfström 2011: 259). This leads us to conclude that students may need on-going education to appreciate just why particular practices are ethically significant ${ }^{4}$ in order to play their part in the upholding of the ethical environment.

\section{The ethical environment: academics}

Whilst the professional identity of academics is well established in the research (see for example Gordon and Whitchurch, 2010) this tends to focus on individuals' perceptions of their role as a teacher rather than any responsibility for their part in this. We know more about student behaviour than we do about institutional compliance practices; we know far more about such practices than we do the views of academics. Yet this lack of 'academic voice' can unintentionally leave a weakness in creating an ecology capable of supporting the ethical environment covering assessment in HEls. For example, Nuss (1984) found that over half of the faculty questioned said that they rarely discussed university policies or their educative responsibilities concerning academic dishonesty with their students. More recent research tentatively suggests that compliance and education are 'two sides of the same coin' and that such discussions should be essential to ensure that students understand key codes and regulations (Zwagerman 2008, Baker 2013).

Sustaining an ethical environment is complex and communicating these values and commitments to others can be difficult and even unpleasant. For example, codes need to be reinforced by surveillance and action in order to be effective. It is not enough for academics simply to disapprove of a student's cheating behaviour, they need to actively confront it regardless of how uncomfortable they

${ }^{4}$ We thank Professor Judith Suissa for this particular insight. 
may feel about this (Hard, Conway et al. 2006, Hutton 2006); failure by staff to do this may lead students to believe that they can get away with deception, thus increasing the overall frequency of such behaviours (Hard, Conway et al. 2006).

This study is a starting point for considering how assessment is situated within the construct of a broader ethical environment in education. We believe that where academics are unwilling to play their part, the overall ethical environment of the university is undermined and this has the potential to damage both assessment practice and public trust in the whole system. Approaching such fundamental ethical considerations can involve sensitive discussions with academic peers in order to elicit their views.

\section{Method}

The research reported here attempts to reframe how academics think about assessment as an integral aspect of the ecologies that exist within the concept of an ethical environment of an HEl. Three research questions guided the exploratory empirical research:

a) How can we conceptualise the ethical environment of assessment in higher education?

b) What sustains this environment?

c) How do academics understand their role within the ethical environment?

To explore these questions, we designed an anonymous questionnaire survey that allowed respondents to comment freely on what may be considered sensitive issues. Given that this research is exploratory in nature and received no funding, we urge caution over assuming any generalizability due to the small numbers of participants involved. The samples were necessarily small as this study was (a) investigatory and (b) limited due to stipulations from the $\mathrm{HEI}$ ethical clearance agreements given for such work. We have limited our ecology to three groups (the university, the faculty and the students) to examine our hypothesis that academics are best placed to provide the education needed for compliance. This is not to say that they do this alone: student services, academic support staff and librarians amongst others are important contributors.

Data collection tools were piloted, adjusted and a final copy set up with an email link sent out to prospective respondents. We recruited participants via a snowball sampling technique (Bailey 1994); there were several reasons for adopting this methodology. First, snowball sampling is a well-known technique for inquiry into sensitive or ethical topics (Faugier and Sargeant 1997, Penrod, Preston et al. 2003, Noy 2008). Secondly, snowball sampling can be an effective tool for targeting populations (e.g. academics) that are defined by their activities (Sudman and Kalton 1986). Whilst the technique is sometimes criticized as only drawing from 'people like us' (Biernacki and Waldorf 1981, Penrod, Preston et al. 2003), we viewed this as a strength: we wanted to recruit other, similar academics and only from this category. The third reason was purely pragmatic: in order to secure ethical clearance, we needed a technique that ensured a complete separation of researcher from those being researched. 
The software application, Survey Monkey ${ }^{5}$ was used to produce an online survey comprising both open and closed questions relating to respondents' work history and attitudes to teaching and learning. The survey included three assessment-related case studies (see Table 1) and respondents were invited to comment on each one. To meet word limits, the cases have been summarised here.

Table 1: Fictitious case studies used in the survey

\section{TABLE ONE}

\section{Data}

The survey invitation was sent to 102 academics and 33 completed it, of these 31 were either currently working, or had worked in universities. Due to the small numbers involved in this study, it was not viable to conduct any tests for significance, but the data were summarised using descriptive statistics.

Questions 1 to 4 asked respondents about their employment experience: they comprised senior/lecturers $(n=14)$, professors $(n=11)$ and principal lecturers, readers, teaching fellows and one academic developer $(n=8)$. Almost half $(n=15)$ of our respondents had worked in HE for 16 years or more and only three had worked for five years or fewer in this sector. Most respondents $(n=25)$ indicated that teaching formed more than $50 \%$ of their workload and thirteen said that research formed over half of their workloads. Four people had teaching-only contracts; three taught both undergraduate and postgraduate students and one was a school experience tutor.

Most HEl assessment now takes place within Virtual Learning Environments (VLEs), so questions 5 to 8 focused on the participants' use and knowledge of these. The majority of respondents $(n=28)$ had used a VLE and of these, 17 had used it for a range of assessment purposes (see Table 2).

Table 2: Summary of responses to Q7

\section{TABLE TWO}

We were interested in the use of VLEs to check for plagiarism (as one of our "big three') and in particular, the ways in which academics felt they had responsibility for this seemingly technical process. Table 3 summarises the results.

\section{Table 3: Summary of responses to Q8 - Checking processes}

\section{TABLE THREE}

Sixteen respondents said that they checked all work despite the considerable time this involved; whereas six checked only a small sample of student work. Responses uncovered a variety of practices related to the use of software to check for plagiarism and whilst most respondents did use Turnitin, others rejected it for a range of reasons and these appear to link to the nature of compliance. Three academics believed that they could spot plagiarism when it occurs; one said that

\footnotetext{
${ }^{5}$ https://www.surveymonkey.co.uk/
} 
they "did not have time to check such things" and one said "I trust my students". Respondents also cited further reasons for not checking: three said that the university administrators conducted the checks; and one claimed "I don't agree with all criteria for plagiarism or whether it is as significant in the early stages of coming to understand academic life". The results also revealed that of respondents who were not in favour of using anti-plagiarism software $(n=11)$, the majority were professors $(n=7)$ they explained their attitudes with reference to experience/ability to ascertain cheating, saying things such as "I can spot when they plagiarise" or "I can tell whether the work is suitable".

Such comments suggest that perhaps more experienced academics seem to view the process of checking for plagiarism (or other types of cheating) as unnecessary given that they either believe they can identify its occurrence or that the students should be trusted to undertake such check themselves. Such responses led us to characterise the overall data within two themes: Responsibility and Roles, these are discussed in more detail in the following section.

\section{Discussion}

A range of inter-connected categories was created to characterise the data from the case studies and from the responses to questions 7 and 8 . In what follows, we draw attention to the two most significant themes which emerged and suggest ways in which this could be understood: firstly, Responsibility and second, The academic role.

\section{Theme - Responsibility}

This research found that academics could hold complicated and often contrasting views on defining their role in supporting an ethical environment in assessment (Bruton \& Childers, 2016). The most influential contextual variable was found to be their views on overall responsibility: whilst many were happy to accord the main responsibility to other parties in the ecology (students or the university), others characterised it as a shared venture.

Three respondents reminded us that the tutor generally has control over the process of assessment. Where misunderstandings arise, some of the academics believed it was because they had somehow failed in the task of assessment design. Despite one academic saying they believed that they had a "good moral compass", many still wanted further guidance as they recognised the subjectivity in the marking practice and could not guarantee impartiality (Taras and Davies, 2017). Participants agreed that they could initiate the institutional procedures that support assessment; thus positioning themselves as 'holders of ethical standards' into a particular 'received' academic culture. However, three were wary of overdependence on institutional structures alone for the sustenance of an overall ethical environment. One said: "I feel strongly that "frameworks", "dialogue" and "training" etc. are merely attempts to bureaucratise something that is simply not amenable to bureaucratic interference. It's probably only a matter of time before staff and students alike are required to demonstrate "ethical skills". Such a view is in line with Small's (2001) concerns that questions of ethics are not dealt with easily within compliance procedures. 
Such compliance procedures, underpinned by university policies, usually rely on tutors upholding such regulations, but some of our respondents were failing in this regard. For example, one commented on the use of anti-plagiarism software, claiming that "the institution requires it but I don't do any checking myself. The students can check their own work now". Such a response seems symptomatic of the now out dated view that this responsibility should rest entirely with students. Yet four respondents viewed the responsibility for ethical behaviour in assessment to rest mostly with the students. Whilst there may have been some disagreement over who should ultimately hold responsibility as these 'holders of ethical standards', some respondents felt that they needed further clarity regarding their role as an assessor, one explained that: "...institutional structures [are needed] to support assessment in ways that promote ethical behaviours". Such reflections seem to underline the need for a review of practice that acknowledges the complexity of these concerns because as Howard (2007) argues this is not simply a technical matter, it requires a degree of ethical consideration on the part of the academic.

We found it curious that just five respondents saw the upholding of the ethical environment as a shared responsibility. Undoubtedly, the changing terrain of higher education in the UK makes this ideal increasingly hard to achieve. Some of our respondents stated that they felt ill-equipped to deal with troubling situations due to a lack of support from their institutions, a factor also identified by other research, see Bruton and Childers (2016). Nevertheless, developing a shared conception of an ethical environment would require an institution-wide 'buy-in'. As one of our respondents explained: "... it's about the wider flourishing and growth of the academic community and all of its members". Despite such views which might link the ecology of individual HEls into a broader ethical environment, sceptics might suggest that too close an alignment of the university with the overall values of society merely causes staff and students to enter into "Faustian bargains" (Bruton and Childers 2016:X) where in ethics are influenced by accountability-driven educational aims.

Some respondents were reluctant to embrace the codification of particular ethical instances within universities - the strong sense of individualism and personal integrity still underpinning academic freedom in UK HEls led to contrasting perspectives on responsibility. One respondent argued that we should not presume that ethics "... fits into a self-contained box separate from other aspects of teaching and learning" in line with findings by Small (2001). Two other respondents felt personally accountable for the ethical implications of their work. One stated, "It is important that staff model exemplary ethical behaviour in all aspects of their work and explicitly stress the importance of these issues and attributes". The overall picture that emerged suggests academics would welcome further clarity around the ethical issues involved in their professional responsibility and how to put this into practice.

\section{Theme: The academic role}

The second variable of interest is characterised in the ways in which academics perceived their particular roles as a part of the overall ecology. There is some overlap between the way in which our respondents saw responsibility for the ethical environment and their view of their professional role as an academic. 
Nevertheless, the study highlighted elements associated with values that may have been underplayed if viewed soley as responsibility.

One sub-group of survey respondents comprised those who recognised that their personal and professional attributes were intertwined: in other words, the qualities of an ethical lecturer were more or less identical with those of an ethical person, much in line with the findings of Robie and Kidwell (2003). One respondent commented that: "an ethical environment is not just about academia, but life generally". This respondent seemed to acknowledge the overlap between the personal and the institutional as being something far more expansive than regulations and codes could encompass. Another respondent described it as "... an environment that I was used to throughout my academic life as well as the life I am living now". Fourteen respondents believed that personally they needed to demonstrate a commitment to shared values, common goals and openness: the same features needed to support the overall ethical environment of the university. They saw their role as encouraging the development of the same personal attributes in their students, for example "treating each other with respect, honesty, fairness and transparency". But, others took a less sanguine view, arguing that being ethical as a person was different to academically inappropriate behaviour and that it was the role of the academic to ensure assessment tasks ruled out opportunities for such behaviour. One respondent went so far as to claim that the student in Case Study 1 who used feedback without contributing was actually being 'quite smart' - but not necessarily unethical.

Our findings tentatively suggest that there was a further sub-group of respondents who viewed their role as firmly aligned with the regulations of their institution (compliance) and consequently appear to believe that any resultant blame for misconduct must then rest with their students (McQueen, 2014; Peterson et al, 2011). Some respondents accepted that academics had a responsibility for managing problems within their student cohorts as a part of their professional role. However, unless their institution compelled them to act, they felt no personal responsibility to do so.

Despite their apparent differences in approach, the two sub-groups identified above appeared to agree on elements of their role and how it is enacted (suggesting that compliance needs education to be fully realised). For example, institutions tend to have very carefully defined procedures in this area, nevertheless, several respondents from both groups said that students need to understand the normative concerns relating to their studies if we wish them to choose to act ethically (education). This supports research by McCabe and Trevino (1993) (amongst others) on student behaviours that the understanding of honour codes and policies can be a key factor in their success.

Despite some respondents saying that they needed more time with students to discuss such ethical issues, there was a disconnect between their claims and their actions. Consistent with the findings of Everett (2007), the respondents agreed that such discussions with students should be happening, but few academics were actually doing so. They claimed that institutional difficulties hampered the respondents' best intentions with a lack of time $(n=21)$; lack of training $(n=18)$; lack of clear assessment frameworks $(n=24)$ or a need for improved dialogue with 
students $(n=25)$ all being cited. However, the majority were seeking support for developing ways in which such issues could be embedded in their practice.

\section{Conclusion}

Carr (2001) reminds us that education is essentially a moral practice and ethical deliberation lies at its heart. All educators contribute in some way towards the support and well being of a healthy ethical environment not simply within their educational setting, but usually in a broader context beyond the doors of the school, college or university. The value-laden character of our roles as teachers can and should inform our pedagogy, including our attitudes and responses to assessment. With this in mind, we make three final points:

First, our suggestion of an overall framework of an ecology (comprising the institution, the academics and students) that exists within the ethical environment of the university brings together what are often viewed as disparate and sensitive issues. As previously suggested by Raisner (1997) this kind of model enables us to go beyond good/bad behaviour to consider the practical problems within this debate, and to identify the practical problems that need further exploration. We argue that being 'ethically aware' is a critical factor in the development of academic competence for all parties as part of the solution. How this might be achieved may look different in practice with different HEls prioritising a variety of pedagogical practices.

Secondly, institutionalising ethics through an over-reliance on codes alone could truncate our ability to think and act in new situations therefore we need a greater understanding of the relationship between compliance and education. This quintessentially theoretical work could then lay the foundation for how HEls might combine both aspects and enable us to adapt more effectively to new and challenging situations.

Thirdly, this particular study of the views of academics in HEls in the UK advances the literature in this area in three ways:

a) it identified two significant themes - responsibility and the academic role, neither of which are mentioned in any of the attendant literatures covering the ethical environment or its ecologies.

b) it suggests that many academics still lack clarity over how to understand the values implicit in their professional role responsibilities.

c) it suggests a need, on the part of universities and academics, to invoke and support willingness to 'try something new' that might go beyond current practices to fulfil the ethical assessment practice in HEls.

In the quest for improved ways in which to conceptualise and frame important values that lie at the heart of what it is to be an $\mathrm{HEI}$ in a continuously shifting educational landscape, the research reported here suggests some ways forward. We hope to secure funding to extend the scope of the study with larger numbers of participants so as to be able to make some stronger claims. Small-scale studies such as this one may initially appear limited in their scope, yet they serve to identify key areas of our academic practice in need of further exploration. 


\section{References}

Adams, J. S., A. Tashchian and T. H. Shore (2001). "Codes of ethics as signals for ethical behavior." Journal of Business Ethics. 29(3), 199-211.

Allen, J., Fuller, D. and Luckett, M. (1998). "Academic integrity: Behaviors, rates, and attitudes of business students toward cheating." Journal of Marketing Education 20(1), 41-52.

Arnold, V., Lampe, J. C. and Sutton, S. G. (2016). Understanding The Factors Underlying Ethical Organizations: Enabling Continuous Ethical Improvement. Journal of Applied Business Research (JABR), 15(3), 1

Auger, G. A. (2013). "Missing citations, bulking biographies \& unethical collaboration: Types of cheating among public relations majors." Journalism \& Mass Communication Educator 68(2), 150-65. Bailey, K. D. (1994). Methods of social research, New York, The Free Press.

Baker, D. F. (2013). "When Moral Awareness Isn't Enough Teaching Our Students to Recognize Social Influence." Journal of Management Education 38(4), 511-532.

Biernacki, P. and Waldorf, D. (1981). "Snowball sampling: Problems and techniques of chain referral sampling." Sociological methods \& research. 10(2), 141-163.

Bodkin, H. (2017). Medical students at University of Glasgow told to resit exam after 'collusion uncovered'. The Telegraph, URL available at http://www.telegraph.co.uk/news/2017/03/27/medicalstudents-atuniversity-glasgow-told-resit-exam-collusion/

Brown, B. S. and Mclnerney, M. (2008). "Changes in academic dishonesty among business students in the United States, 1999-2006." International Journal of Management 25(4), 621.

Bruton, S. and Childers, D. (2016) The ethics and politics of policing plagiarism: a qualitative study of faculty views on student plagiarism and Turnitin $\AA$, Assessment \& Evaluation in Higher

Education, 41:2, 316-330.

Carr, D. (2001). "Educational philosophy, theory and research: A psychiatric autobiography." Journal of Philosophy of Education 35(3), 461-476.

Collini, S. (2012). What are universities for? Penguin, UK.

Comas-Forgas, R. and Sureda-Negre, J. (2010). "Academic plagiarism: Explanatory factors from students' perspective." Journal of Academic Ethics 8(3), 217-232.

Coren, A. (2012). "The theory of planned behaviour: Will faculty confront students who cheat?" Journal of Academic Ethics 10(3), 171-184.

Dalton, D. and Radtke, R. R. (2013). The Joint Effects of Machiavellianism and Ethical Environment on Whistle-Blowing. Journal of Business Ethics, 117(1), 153-172.

Dore, R. (1979). The Diploma Disease. Education, Qualification and Development. (London, Institute of Education, University of London).

Dowling, W. C. (2003). "Meaningless grades and a new dishonesty." Academic Questions 16(4), 57. Everett, J. S. (2007). "Ethics education and the role of the symbolic market." Journal of Business Ethics 76(3), 253-267.

Faugier, J. and Sargeant, M. (1997). "Sampling hard to reach populations." Journal of advanced nursing 26(4), 790-797.

Gordon, G. and Whitchurch, C. (2009) Academic and Professional Identities in Higher Education: The Challenges of a Diversifying Workforce. London, Routledge.

Hard, S. F., Conway, J. M. and Moran, A. C. (2006). "Faculty and college student beliefs about the frequency of student academic misconduct." The Journal of Higher Education. 77(6), 1058-1080. Haydon, G. (2004). "Values education: sustaining the ethical environment." Journal of Moral Education 33(2), 115-129.

Haydon, G. (2006). Education, philosophy and the ethical environment, Abingdon, Oxon, Routledge. Hogue, C.C. 1984. Falls and mobility in late life: An ecological model. Journal of the American Geriatrics Society, 32 (11), 858-861.

Howard, R. M. (2004). "Forget about policing plagiarism: Just teach." Chronicle of Higher Education. B24. http://chronicle.com/article/Forget-About-Policing/2792.

Howard, R. M. (2007). "Understanding 'Internet Plagiarism'." Computers and Composition 24: 3-15. Hutton, P. A. (2006). "Understanding student cheating and what educators can do about it." College Teaching 54(1), 171-176.

Lavine, M. H. and Roussin, C. J. (2012). "From Idea to Action Promoting Responsible Management Education Through a Semester-Long Academic Integrity Learning Project." Journal of Management Education 36(3), 428-455.

Löfström, E. (2011). "'Does Plagiarism Mean anything? LOL." Students' Conceptions of Writing and Citing." Journal of Academic Ethics 9(4), 257-275. 
Love, K. (2008). "Higher education, pedagogy and the 'customerisation' of teaching and learning." Journal of Philosophy of Education 42(1), 15-34.

Malgwi, C. and Rakovski, C. (2009). "Combating academic fraud: are students reticent about uncovering the covert?" Journal of Academic Ethics 7, 207-221.

McCabe, D. (1993). "Faculty responses to academic dishonesty: the influence of student honor codes." Research in Higher Education 34(5), 647-658.

McCabe, D. (2001)."Cheating: Why students do it and how we can help them stop." American Educator Winter. 38-43.

McCabe, D. L. and Trevino, L. K. (1993). "Academic dishonesty: Honor codes and other contextual influences." Journal of higher education. (64), 522-538.

McCabe, D. L. and Trevino, L. K. (1996). "What we know about cheating in college longitudinal trends and recent developments." Change: The Magazine of Higher Learning 28(1), 28-33.

McCabe, D. L., Trevino, L. K. and Butterfield, K. D. (2002). "Honor codes and other contextual influences on academic integrity: A replication and extension to modified honor code settings." Research in Higher Education. 43(3), 357-378.

McCarthy, E. (2012). Ethics and Ecologies: Negotiating Responsible and Sustainable Business in Ireland, PhD Thesis, Rice University, Houston, USA.

McLafferty, C. L. and Foust, K. M. (2004). "Electronic plagiarism as a college instructor's nightmarePrevention and detection." Journal of Education for Business. 79(3), 186-190.

McQueen, H. (2014). Roles, Rights, and Responsibilities in UK Education Tensions and

Inequalities (First ed.), Basingstoke, Palgrave Macmillan.

Meyers, C. (2004). Institutional culture and individual behavior: Creating an ethical environment.

In Science and Engineering Ethics, (10), 269-276.

Molnar, K. K. and Kletke, M. G. (2012). "Does the type of cheating influence undergraduate students' perceptions of cheating?" Journal of Academic Ethics. 10(3), 201-212.

Natale, S. M. and Doran, C. (2012). "Marketization of education: an ethical dilemma." Journal of Business Ethics 105(2), 187-196.

Newman, Turner \& Turner, F. M. (1996). The idea of a university, New Haven: Yale University Press.

Nijhof, A., Wilderom, C. and Oost, M. (2012). "Professional and institutional morality: building ethics

programmes on the dual loyalty of academic professionals." Ethics and Education. 7(1), 91-109.

Noy, C. (2008). "Sampling knowledge: The hermeneutics of snowball sampling in qualitative

research." International Journal of social research methodology. 11(4), 327-344.

Nuss, E. M. (1984). "Academic integrity: Comparing faculty and student attitudes." Improving College and University Teaching. 32(3), 140-144.

Oakeshott, M. (2003). The Idea of a University. Academic Questions, 17(1), 23-30.

Penrod, J., D. Preston, B., Cain, R. E. and Starks, M. T. (2003). "A discussion of chain referral as a method of sampling hard-to-reach populations." Journal of Transcultural Nursing. 14(2), 100-107.

Peterson, E., Rubie-Davies, C., Elley-Brown, M., Widdowson, D., Dixon, R. and Irving, S. (2011). Who is to Blame? Students, Teachers and Parents Views on Who is Responsible for Student

Achievement. Research in Education, 86(1), 1-12.

Raisner, J.A. (1997) Using the "Ethical Environment" Paradigm to Teach Business Ethics: The Case of the Maquiladoras. Journal of Business Ethics. 16: 1331-1346

Robie, C. and Kidwell, R. E. 2003. The "ethical" professor and the undergraduate student: Current perceptions of moral behaviour among business school faculty. Journal of Academic Ethics, 1, 153173.

Sallis, E. and Sallis, K. (1988). People in organisations. Basingstoke, Macmillan Education.

Small, R. (2001). "Codes are not enough: What philosophy can contribute to the Ethics of Educational Research." Journal of Philosophy of Education. 35(3), 387-407.

Smyth, L. S., Davis, J. R. and Kroncke, C. O. (2009). "Students' perceptions of business ethics: Using cheating as a surrogate for business situations." Journal of Education for Business. 84(4), 229-239.

Spain, J. W. and Robles, M. M. (2011). "Academic Integrity Policy: The Journey." Business

Communication Quarterly. 74(2), 151-159.

Sudman, S. and Kalton, G. (1986). "New developments in the sampling of special populations." Annual Review of Sociology. (12), 401-429.

Taras, M. and Davies, M. (2017) 'Assessment beliefs of higher education staff developers', London

Review of Education, 15(1), 126-140.

Tomlinson, M. (2010). Investing in the self: structure, agency and identity in graduates'

employability. Education, Knowledge and Economy, 4(2), 73-88.

Trautner, M. N. and Borland, E. (2013). "Using the Sociological Imagination to Teach about Academic Integrity." Teaching Sociology: 41(4), 377-388 
Visser, M. (2007). The social ecological model as theoretical framework in community psychology. Community psychology: Analysis, context and action, Cape Town, University of Cape Town Press. Walker, J. (2010). "Measuring plagiarism: researching what students do, not what they say they do." Studies in Higher Education. 35(1), 41-59.

Warren, K.J. and Cheney, J. (1991). Ecological Feminism \&Ecosystem Ecology 1.Hypatia, 6(1), 179197.

Westacott, E. (2008). "Academic dishonesty and the culture of assessment." Journal of the National Collegiate Honors Council--Online Archive. 9(2), 65.

Zwagerman, S. (2008). "The scarlet P: Plagiarism, panopticism, and the rhetoric of academic integrity." College Composition and Communication. 59(4), 676-710. 